\title{
Neurological abnormalities and neurocognitive functions in healthy elder people: A structural equation modeling analysis
}

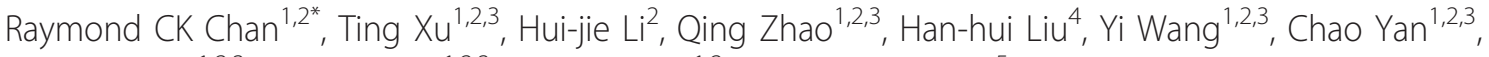 \\ Xiao-yan Cao ${ }^{1,2,3}$, Yu-na Wang ${ }^{1,2,3}$, Yan-fang Shi, ${ }^{1,2}$ and Paola Dazzan ${ }^{5}$
}

\begin{abstract}
Background/Aims: Neurological abnormalities have been reported in normal aging population. However, most of them were limited to extrapyramidal signs and soft signs such as motor coordination and sensory integration have received much less attention. Very little is known about the relationship between neurological soft signs and neurocognitive function in healthy elder people. The current study aimed to examine the underlying relationships between neurological soft signs and neurocognition in a group of healthy elderly.

Methods: One hundred and eighty healthy elderly participated in the current study. Neurological soft signs were evaluated with the subscales of Cambridge Neurological Inventory. A set of neurocognitive tests was also administered to all the participants. Structural equation modeling was adopted to examine the underlying relationship between neurological soft signs and neurocognition.

Results: No significant differences were found between the male and female elder people in neurocognitive function performances and neurological soft signs. The model fitted well in the elderly and indicated the moderate associations between neurological soft signs and neurocognition, specifically verbal memory, visual memory and working memory.

Conclusions: The neurological soft signs are more or less statistically equivalent to capture the similar information done by conventional neurocognitive function tests in the elderly. The implication of these findings may serve as a potential neurological marker for the early detection of pathological aging diseases or related mental status such as mild cognitive impairment and Alzheimer's disease.
\end{abstract}

Keywords: neurological soft signs, neurocognitive impairments, elderly, Chinese

\section{Background}

Neurological soft signs are minor neurological abnormalities in sensory and motor function commonly reported in disorders such as schizophrenia spectrum disorders [1,2], autism spectrum disorders [3], and obsessive-compulsive disorders [4]. Recent studies suggest that healthy people at different developmental stages in their lives also exhibit differential base-rates of neurological signs [5-7]. This is particularly true for elderly individuals, because neurological signs increase

\footnotetext{
* Correspondence: rckchan@psych.ac.cn

${ }^{1}$ Neuropsychology and Applied Cognitive Neuroscience Laboratory, Institute of Psychology, Chinese Academy of Sciences, Beijing, China

Full list of author information is available at the end of the article
}

with advancing age [8]. Past research on neurological abnormalities in elderly individuals has primarily focused on evaluating extrapyramidal disturbances or focal signs, which are collectively known as "hard" signs [9-13]. These are impairments of basic motor and sensory function, corresponding to alterations in focal and localized brain areas, such as the basal ganglia [14], and they have been reported as increased in aging populations. In contrast, although minor neurological abnormalities have been observed in pathological aging populations, such as Alzheimer's disease and Parkinson's disease, the prevalence of neurological soft signs (such as rapid alternate finger tapping or astereognosis) in the healthy aging population has not been examined.

\section{C) Biomed Central}


In contrast to hard signs, the presence of neurological soft signs has been thought to indicate a diffuse damage of the brain, not related to damage of a specific brain region. However, recent structural imaging studies show that neurological soft signs are significantly associated with volume changes in specific brain regions, and reductions in gray matter in both neuropsychiatric disorders and healthy volunteers $[15,16]$. Moreover, most recent functional imaging studies also show that, although no specific single region is responsible for these neurological soft signs, there is a specific neural network linking the right inferior prefrontal cortex to the middle prefrontal cortex underlying their presence $[17,18]$.

This is particularly interesting considering that the frontal hypothesis of cognitive aging suggests that the prefrontal cortex deteriorates earlier and disproportionately in comparison to the rest of the cortex [19], showing a decline in volume, white matter density, and synaptic density [20]. Consistent with changes in frontal cortex, is the robust finding of a general decline in executive function (critically regulated by the frontal cortex) associated with physiological aging processes (e. g., [21-23]). It is of note that in fact neurological soft signs and cognitive deficits have been thought to be functional correlates of the same pathophysiological substrate.

Interestingly, a recent study from our group [24], adopting structural equation modeling, showed that motor coordination, sensory integration, and disinhibition contributed to the latent construct of neurological soft signs, whereas the subset of neurocognitive function tests contributed to the latent constructs of executive attention, verbal memory, and visual memory. Greater evidence of neurological soft signs is associated with more severe impairment of executive attention and memory functions in a group of patients with schizophrenia and healthy controls independently.

Therefore, it is important to explore the prevalence rates of neurological soft signs, and their relationship to executive and other neurocognitive functions in the cognitively intact elderly people. Unfortunately, existing studies have been limited to the evaluation of neurological hard signs, and almost all of them have evaluated individuals of Caucasian origin. In contrast, very little is known about individuals from other ethnic groups such as the Chinese.

The purpose of the current study was to examine the underlying relationship between neurological soft signs and neurocognitive function in a sample of healthy Chinese elderly people by means of a standardized neurological signs scale. Given the previous findings of more or less equivalent constructs between neurological soft signs and neurocognitive functions in schizophrenia and healthy young adults, it was hypothesized that a similar structural equation model would be observed in healthy elderly participants

\section{Method}

\section{Ethics Statement}

The present study was approved by the ethics committee of the Institute of Psychology, Chinese Academy of Sciences. Written informed consent was obtained by participants.

\section{Participants}

One hundred and eighty healthy elderly participants (86 men and 94 women) were recruited from several provinces of China, through household visits and local advertisements. Exclusion criteria were: (1) a history of head trauma resulting in loss of consciousness for $>1 \mathrm{~h}$; (2) a diseases of the central nervous system; (3) a history of any psychotic disorder; (4) current and past alcohol or substance abuse.

All participants were evaluated with the Mini Mental State Examination (MMSE) [25], which includes tests of learning, memory, and verbal ability, to assess cognitive dysfunction. An MMSE score lower than 24 points was considered to indicate a probable diagnosis of Alzheimer Disease [26].

\section{Materials and procedure}

The Cambridge Neurological Inventory (CNI) was used for the assessment of neurological soft signs [27]. The $\mathrm{CNI}$ has been applied to different age groups in both healthy and clinical Chinese populations $[6,28,29]$. The administration the CNI has been described elsewhere (e.g., [6,27]). In brief, The CNI soft signs assessment consisted of motor coordination (e.g., rapid finger tapping, fist-edge-palm), sensory integration (e.g., astereognosis, agraphesthesia), and inhibition (e.g., mirror movement, eye blink while performing eye tracking). Each item were assessed as either "absent" (which covered the normal or equivocal scale scores) or "present" (which covered the abnormal or grossly abnormal scale scores). Items that could be scored on both the left and the right were each treated as independent scores. All items were rated by a trained research assistant. We administered the CNI in a standardized manner, as specified for each item, and according to a fixed order.

The logical memory and visual reproduction subtests selected from the Chinese version of the Wechsler Memory Scale-Revised [30] were used to measure verbal memory and visual memory. For logical memory, the participants was told a short story and asked to recall it immediately and again 30 minutes later. For visual reproduction, the participant was shown two pictures 
(one at a time) for $10 \mathrm{~s}$ each, and asked to draw them immediately and again 30 min later.

Working memory was assessed by the Chinese version of the Letter-Number Span Test (Chinese LN span) [31] and the forward and backward digit span tests. In the Letter-Number sequencing task, the experimenters verbally presented a specified sequence of random digits (1 to 9) mixed with Chinese characters (in a specific sequence, such as A, B, C in English) at a rate of one per second. Participants were asked to rearrange the order so that the digits came first, from small to big, and then the characters, in sequence. The number of digits and letters increased with 1 digit or character until the participant incorrectly repeated two trials of the same length.

\section{Data analysis}

We focused on evaluating the relationship between neurological soft signs and neurocognitive function with structure equation model (SEM). It is hypothesized that neurocognitive functions co-vary with neurological soft signs. Neurocognitive functions and neurological soft signs were latent variables, as measured by the corresponding scales. Specifically, Logical Memory Immediate Recall and Logical Memory Delayed Recall were indices of "Verbal Memory"; and the Visual Reproduction Immediate Recall and Visual Reproduction Delayed Recall were indices of "Visual Memory"; the number of correct passed and the number of longest passed items described the "Working Memory". On the other hand, the Motor Coordination, Sensory Integration, and Disinhibition contributed to "Neurological Soft Signs". The relationship between neurocognitive functions, i.e., Verbal Memory, Visual Memory, and Working Memory and neurological soft signs (Motor Coordination, Sensory Integration, and Disinhibition) were covariant.

The SEM was conducted using LISREL 8.70 for Windows. All the variables were standardized before being entered in the model. Five fit indices were recorded to evaluate the fitness of goodness of the model. They are the Root Mean Square Error of Approximation (RMSEA), Normed Fit Index (NFI), Non-Normed Fit Index (NNFI), Comparative Fit Index (CFI), and Goodness of Fit Index (GFI). These indices represent the improvement in fit between the assumed model and the baseline model of uncorrelatedness between the observed variables. The first four fit indices values of .90 or above, and an RMSEA value of .08 or less indicated the model adequately fits the data [32].

\section{Results}

The age of the participants ranged between 60 to 96 years (mean age 69.35, SD = 6.53). We divided 180 participants into three group according to the age. The summary scores of neurocognitive function and soft signs were displayed in Table 1 . There was a significant tendency for groups with elder subjects have worse performance on logical memory, visual memory (delay score) and soft signs total and sensory integration score. However, the tendency was plus to nonsignificant and significant for the neurocognitive tasks and soft signs, respectively, when education was took in to account as covariance in ANCOVA.

There were no differences in age between males and females $(t=0.48, p=0.63)$. The mean years of education was 6.84 ( $\mathrm{SD}=4.38)$, and education in males was higher than in females $(\mathrm{t}=2.07, \mathrm{p}=0.04)$. The MMSE scores did not differ between males and females $(\mathrm{t}=$

Table 1 Descriptive statistics for neurocognitive functions and neurological soft signs scores for different age groups

\begin{tabular}{|c|c|c|c|c|c|c|c|c|}
\hline \multirow[t]{2}{*}{ Age range } & \multicolumn{2}{|c|}{$\begin{array}{c}60-69 \\
(n=109)\end{array}$} & \multicolumn{2}{|c|}{$\begin{array}{c}70-79 \\
(n=56)\end{array}$} & \multicolumn{2}{|c|}{$\begin{aligned} &=80 \\
&(n=15)\end{aligned}$} & \multicolumn{2}{|c|}{ ANOVA $(d f=2,177)$} \\
\hline & Mean & SD & Mean & SD & Mean & SD & $\mathrm{F}$ & $p$-value \\
\hline Age (years) & 65.07 & 2.80 & 73.91 & 2.79 & 83.40 & 4.12 & 358.28 & 0.000 \\
\hline Education (number of years) & 26.37 & 3.02 & 25.20 & 3.34 & 24.53 & 3.64 & 3.92 & 0.022 \\
\hline MMSE & 7.70 & 3.90 & 5.57 & 4.52 & 5.27 & 5.70 & 5.73 & 0.004 \\
\hline Logical Memory & 8.63 & 3.89 & 6.93 & 3.94 & 6.27 & 3.79 & 4.98 & 0.008 \\
\hline Logical Memory (Delay) & 6.56 & 3.74 & 4.70 & 3.54 & 4.80 & 3.38 & 5.48 & 0.005 \\
\hline Visual reproduction & 17.06 & 5.21 & 15.25 & 6.16 & 14.47 & 5.33 & 2.85 & 0.061 \\
\hline Visual reproduction (Delayed) & 14.94 & 6.20 & 12.14 & 6.78 & 11.73 & 5.15 & 4.53 & 0.012 \\
\hline LN span items passed & 8.28 & 4.47 & 6.96 & 4.14 & 7.52 & 6.96 & 1.55 & 0.216 \\
\hline LN span longest passed & 3.83 & 1.80 & 3.36 & 1.84 & 3.11 & 2.51 & 1.76 & 0.175 \\
\hline Motor coordination & 1.80 & 1.63 & 2.25 & 1.80 & 2.40 & 1.45 & 1.85 & 0.160 \\
\hline Sensory integration & 1.70 & 1.44 & 2.57 & 1.54 & 2.80 & 1.61 & 8.46 & 0.000 \\
\hline Disinhibition & 1.73 & 1.40 & 2.04 & 1.40 & 2.07 & 1.39 & 1.05 & 0.353 \\
\hline Total NSS score & 5.23 & 3.21 & 6.86 & 3.39 & 7.27 & 3.31 & 5.99 & 0.003 \\
\hline
\end{tabular}

LN span: Letter-Number Span Test; MMSE: Mini Mental Status Examination; NSS: Neurological Soft Signs 
$1.15,0.25)$, with a mean of $25.85(\mathrm{SD}=3.23)$. Table 2 displays the means, SDs and the independent sample ttest results comparison across gender. In neurocognitive and neurological soft signs performance there were also no significant differences between males and females. There was however $.05<p<.10$ in Logical Memory performance, where males performed better than females, and for sensory integration, where females tended to have more sensory integration signs than males. Table 3 shows prevalence rate, chi-square value, and Fisher's $\mathrm{p}$ of neurological soft signs for each item. Only the rate of one item (Graphesthesia R) was significantly different between males and females. On average, there were no significant differences found between males and females in the prevalence rate of individual items of neurological soft signs.

The model showed a good fit of the structure in this elderly sample. Figure 1 shows the structure path and the loadings of the model. The structural paths from neurological soft signs to verbal memory, visual memory and working memory were $-0.49,-0.68$, and -0.70 , respectively. All loadings were statistically significant except the one from neurological soft signs and disinhibition. The chi-square was $60.98(\mathrm{p}<0.001)$ with degree of freedom $=30$. The fitness index indicated relatively well fit of the model, RMSEA $=0.076$, NFI $=0.93$, $\mathrm{NNFI}=0.96, \mathrm{CFI}=0.97, \mathrm{GFI}=0.93$, and Standardized $\mathrm{RMR}=0.064$.

\section{Discussion}

The findings suggest that neurological soft signs are very common among elderly people. Like neurological hard signs such as basal ganglia signs, soft signs appear also to increase in prevalence with advancing age $[5,10]$.

Table 2 Comparison of neurocognitive functions and neurological soft signs between male and female

\begin{tabular}{|c|c|c|c|c|c|c|}
\hline & \multicolumn{2}{|c|}{$\begin{array}{c}\text { Male } \\
(\mathrm{N}=86)\end{array}$} & \multicolumn{2}{|c|}{$\begin{array}{l}\text { Female } \\
(\mathrm{N}=94)\end{array}$} & \multicolumn{2}{|c|}{$\begin{array}{c}\text { t-test } \\
(\mathrm{df}=178)\end{array}$} \\
\hline & Mean & SD & Mean & SD & $\mathrm{T}$ & $\begin{array}{c}\mathrm{p}- \\
\text { value }\end{array}$ \\
\hline Logical memory & 8.50 & 4.06 & 7.36 & 3.85 & 1.93 & 0.055 \\
\hline Logical memory (Delayed) & 6.31 & 3.87 & 5.39 & 3.58 & 1.66 & 0.099 \\
\hline Visual reproduction & 16.85 & 4.96 & 15.76 & 6.08 & 1.33 & 0.187 \\
\hline $\begin{array}{l}\text { Visual reproduction } \\
\text { (Delayed) }\end{array}$ & 14.08 & 6.11 & 13.55 & 6.77 & 0.55 & 0.582 \\
\hline LN span items passed & 8.16 & 4.74 & 7.46 & 5.24 & 0.86 & 0.389 \\
\hline LN span longest passed & 3.85 & 1.90 & 3.36 & 2.08 & 1.53 & 0.129 \\
\hline Motor coordination & 2.00 & 1.71 & 1.98 & 1.66 & 0.08 & 0.933 \\
\hline Sensory integration & 1.85 & 1.35 & 2.26 & 1.68 & -1.79 & 0.075 \\
\hline Disinhibition & 1.69 & 1.36 & 2.01 & 1.43 & -1.56 & 0.120 \\
\hline Total NSS score & 5.53 & 3.32 & 6.24 & 3.38 & -1.42 & 0.158 \\
\hline
\end{tabular}

LN span: Letter-Number Span Test; MMSE: Mini Mental Status Examination; NSS: Neurological Soft Signs
Very few data have been reported on the lifespan performance of neurological soft signs in healthy sample. A longitudinal study has found that neurological soft signs diminished with age from childhood to adolescence [33]. The current study did suggest that the prevalence of neurological soft signs increase with age for elderly people. Though there is formal publishable data specifically for the normal aging sample, the data implicated by the healthy volunteers as controls for Alzheimer's disease suggest a base-rate of soft signs in this sample, with motor coordination signs as the most commonly endorsed items [29]. The significant and robust associations found between neurological soft signs and neurocognitive function were also consistent with findings from studies conducted in individuals with schizophrenia and Alzheimer's disease [29,34-36] suggesting that maybe there is common neural substrates between neurological soft signs and neurocognitve function. Most recently, Chan et al. [24] adopted a structural equation modeling approach evaluating neurological soft signs and conventional neurocognitive functioning in schizophrenia and healthy volunteers, and showed that these two constructs (neurological soft signs and neurocognitive functioning) significantly overlap, with regression coefficients higher than 0.5 , and capture a similar information of these two constructs. Interestingly, the same model was observed in the healthy controls. Taken together, these findings suggest that this model is relatively robust. However, it should be noted that the statistical model cannot confirm that neurological soft signs and neurocognitive function share the same neural substrates. The underlying neural mechanism needs to be further studied by rigorous experimental design for a better understanding of the relationship between neurological soft signs and neurocognitive functions in the near future.

The negative correlation between neurological soft signs and cognitive performance in our study is consistent with the previous findings that have shown that there were significant differences in neurological soft signs between older people with and without cognitive impairment in the Chinese setting. For example, Lam et al. [29] showed that patients with Alzheimer's disease have a significantly higher prevalence of neurological soft signs than those without dementia. In their clinical sample, Lam et al. [29] found the CNI soft signs subscales to be very sensitive in discriminating between cases with dementia and cases without, and this was particularly the case for motor coordination signs and sensory integration signs. Our findings further support this claim; at least it is sensitive enough to detect cognitively impaired and intact cases in terms of motor coordination. Genetic studies from schizophrenia also suggest that $\alpha 7$ nicotinic cholinergic receptor [37], 
Table 3 Prevalence rates of individual neurological soft signs items

\begin{tabular}{|c|c|c|c|c|c|c|}
\hline \multirow[t]{2}{*}{ Item } & \multicolumn{2}{|c|}{$\begin{array}{c}\text { Male } \\
(\mathrm{N}=86)\end{array}$} & \multicolumn{2}{|c|}{$\begin{array}{c}\text { Female } \\
(\mathrm{N}=94)\end{array}$} & \multirow[b]{2}{*}{ chi-square } & \multirow[b]{2}{*}{ Fisher's Exact $p$} \\
\hline & No. & $\%$ & No. & $\%$ & & \\
\hline Finger-thumb tapping $L$ & 1 & $1.16 \%$ & 2 & $2.13 \%$ & 0.255 & 1.000 \\
\hline Finger-thumb tapping $R$ & 1 & $1.16 \%$ & 0 & $0.00 \%$ & 1.099 & 0.478 \\
\hline Finger-thumb opposition L & 13 & $15.12 \%$ & 21 & $22.34 \%$ & 1.530 & 0.255 \\
\hline Finger-thumb opposition R & 19 & $22.09 \%$ & 19 & $20.21 \%$ & 0.095 & 0.855 \\
\hline Mirror $1 \mathrm{~L}$ & 14 & $16.28 \%$ & 20 & $21.28 \%$ & 0.732 & 0.448 \\
\hline Mirror $1 \mathrm{R}$ & 21 & $24.42 \%$ & 19 & $20.21 \%$ & 0.460 & 0.591 \\
\hline Diadochokinesia L & 10 & $11.63 \%$ & 8 & $8.51 \%$ & 0.485 & 0.620 \\
\hline Diadochokinesia R & 9 & $10.47 \%$ & 4 & $4.26 \%$ & 2.585 & 0.150 \\
\hline Mirror $2 \mathrm{~L}$ & 8 & $9.30 \%$ & 15 & $15.96 \%$ & 1.785 & 0.264 \\
\hline Mirror $2 \mathrm{R}$ & 3 & $3.49 \%$ & 10 & $10.64 \%$ & 3.426 & 0.085 \\
\hline Fist-edge palm L & 45 & $52.33 \%$ & 46 & $48.94 \%$ & 0.206 & 0.658 \\
\hline Fist-edge palm R & 34 & $39.53 \%$ & 41 & $43.62 \%$ & 0.308 & 0.650 \\
\hline Oszeretsky test & 40 & $46.51 \%$ & 45 & $47.87 \%$ & 0.033 & 0.882 \\
\hline Extinction & 2 & $2.33 \%$ & 5 & $5.32 \%$ & 1.077 & 0.447 \\
\hline Finger Agnosia L & 45 & $52.33 \%$ & 54 & $57.45 \%$ & 0.476 & 0.549 \\
\hline Finger Agnosia R & 33 & $38.37 \%$ & 43 & $45.74 \%$ & 1.001 & 0.366 \\
\hline Stereognosia L & 7 & $8.14 \%$ & 4 & $4.26 \%$ & 1.181 & 0.365 \\
\hline Stereognosia R & 3 & $3.49 \%$ & 6 & $6.38 \%$ & 0.792 & 0.051 \\
\hline Graphesthesia L & 18 & $20.93 \%$ & 30 & $31.91 \%$ & 2.771 & 0.129 \\
\hline Graphesthesia R & 26 & $30.23 \%$ & 43 & $45.74 \%$ & 4.572 & 0.046 \\
\hline L-R Orientation & 25 & $29.07 \%$ & 27 & $28.72 \%$ & 0.003 & 1.000 \\
\hline Saccade BLK & 5 & $5.81 \%$ & 9 & $9.57 \%$ & 0.885 & 0.412 \\
\hline Saccade Head & 36 & $41.86 \%$ & 31 & $32.98 \%$ & 1.516 & 0.280 \\
\hline Wink & 30 & $34.88 \%$ & 41 & $43.62 \%$ & 1.434 & 0.285 \\
\hline Go/No-Go & 28 & $32.56 \%$ & 44 & $46.81 \%$ & 3.800 & 0.067 \\
\hline
\end{tabular}

catechol-O-methytransferase (COMT) and GRM3 genetic variation [38] may be related to the presence of neurological soft signs. Taken together, the use of neurological soft signs may serve as potential sensitive bedside screening tool for neuropsychiatric or neurodegenerative disorders.

The current study has several limitations. First, our findings should be considered preliminary. Because of the small sample size and the non-stratified sample selection, they cannot be considered to represent prevalence rates of neurological soft signs in Chinese elderly people. The data should not be generalized to the elderly population of China, which has a total population of 1.3 billion. About 100.45 million people are over 65 years of age, occupying $7.69 \%$ of the overall population in China [39]. Secondly, we could not subdivide the sample into subgroups of old-old and oldest-old, because of the relatively limited number of people over the age of 85. Empirical findings suggest that this oldest-old age group is particularly at risk of developing neurological disorders or neurodegenerative illnesses such as dementia or Alzheimer's disease, with prevalence rates as high as $47 \%$ [40]. It could be expected that these age group would therefore show even higher neurological soft signs rates. Third, the current study did not assess IQ, which has been considered to be highly associated with neurological soft signs (e.g., [28]). However, since there were no differences in education (an indirect measure of IQ), and since controlling for neurocognitive functioning did not affect the results, we suggest that the current findings could not be completely explained by potential IQ difference between the two groups.

Notwithstanding these limitations, the current study is one of the very few studies specifically examining the prevalence rates of neurological soft signs in healthy aging people, and Chinese in particular. The observed prevalence of neurological soft signs adds further evidence to the geriatric literature on neurological impairments in cognitively intact people, and may provide a base-rate for identifying a potential clinical cut-off in the near future. The moderate associations of the presence of neurological soft signs in the parent-offspring family units suggest a robust heritability [41]. This study suggests that neurological soft signs may represent a potential neurological marker for the early detection of 


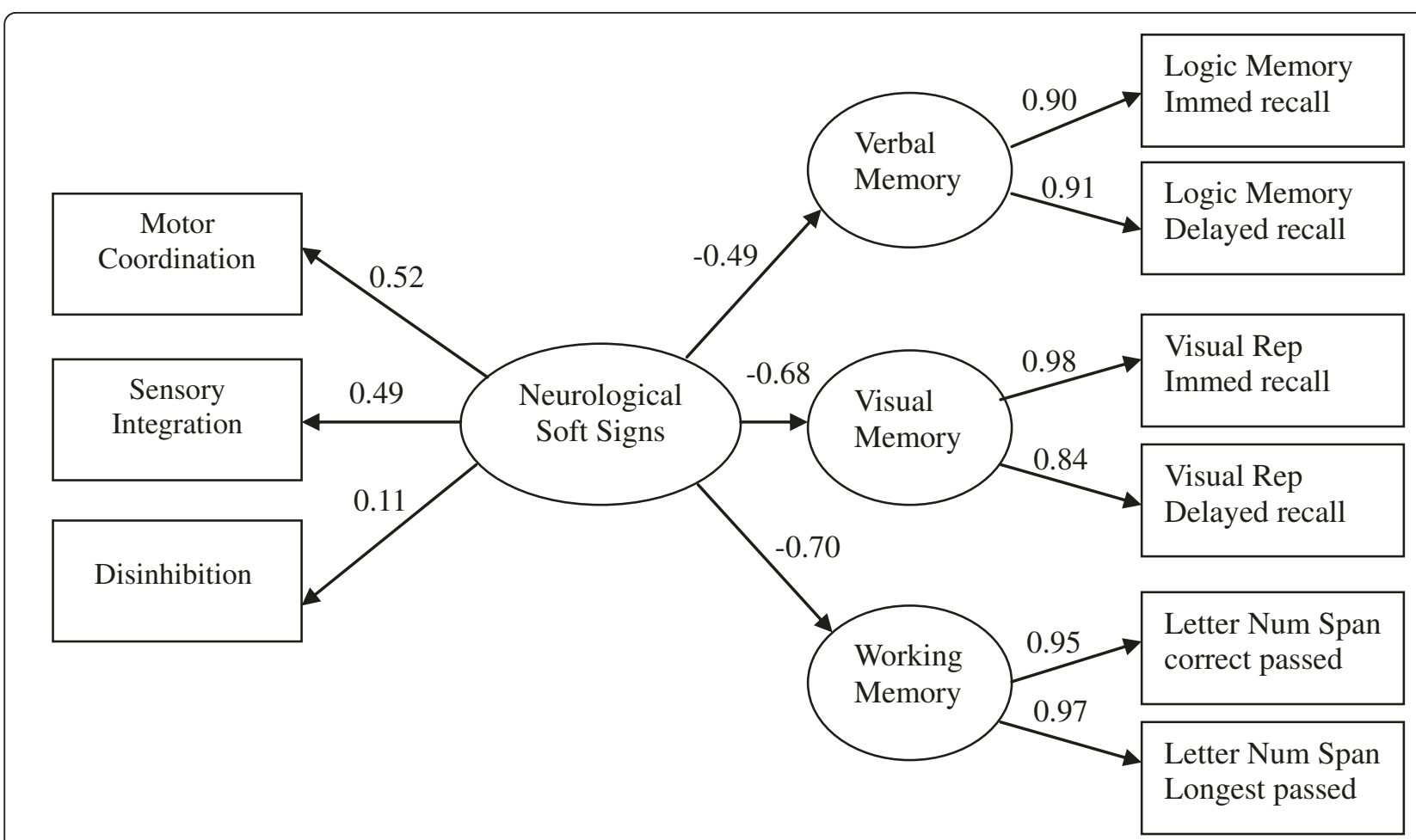

Figure 1 The structure model of influence of soft signs on cognitive function in elderly. Chi-square $=60.98, p<0.001, d f=30, N F I=0.93$ $\mathrm{NNFI}=0.96, \mathrm{CFI}=0.97, \mathrm{GFI}=0.93, \mathrm{RMSEA}=0.076$, Standardized $\mathrm{RMR}=0.064$.

pathological aging diseases such as mild cognitive impairment and Alzheimer's disease. Future studies using a population-based design could be important to cross-validate our findings.

\section{List of abbreviations}

BLK: Blink; CFI: Comparative Fit Index; CNI: Cambridge Neurological Inventory; COMT: catechol-O-methytransferase; GFI: Goodness of Fit Index; IQ: Intellectual Quotient; LISREL: A software for computing the structural equation modeling; L: left; LN span: Letter-Number Span; MMSE: Mini Mental State Examination; NFI: Normed Fit Index; NNFI: Non-Normed Fit Index; R: Right; RMSEA: Root Mean Square Error of Approximation; SEM: structure equation model

\section{Acknowledgements}

This study was supported partially by the Project-Oriented Hundred Talents Programme (O7CX031003), the Knowledge Innovation Project of the Chinese Academy of Sciences (KSCX2-YW-R-131 \& KSCX2-EW-J-8), a grant from the National Basic Research Programme (973 Programme No. 2007CB512302), and a grant from the National Outstanding Young Investigator Award from National Science Foundation of China (81088001). The funding sources had no role in study design, data collection and analysis, decision to publish, or preparation of the manuscript.

\section{Author details}

${ }^{1}$ Neuropsychology and Applied Cognitive Neuroscience Laboratory, Institute of Psychology, Chinese Academy of Sciences, Beijing, China. ${ }^{2}$ Key Laboratory of Mental Health, Institute of Psychology, Chinese Academy of Sciences, Beijing, China. ${ }^{3}$ Graduate School, Chinese Academy of Sciences, Beijing, China. ${ }^{4}$ School of Psychology, Beijing Normal University, Beijing, China. ${ }^{5}$ Institute of Psychiatry, King's College, London, UK.

\section{Authors' contributions}

RCKC conceived the idea, designed the study, and wrote the first draft of the paper. XT collected and analyzed the data. HJL, QZ, HHL, YW, CY, XYC, YNW, YFS collected the data and assisted data analysis. PD participated in writing up the paper. All authors read and approved the final manuscript.

\section{Competing interests}

The authors declare that they have no competing interests.

Received: 19 March 2011 Accepted: 10 August 2011

Published: 10 August 2011

\section{References}

1. Torrey EF, Bowler AE, Taylor EH, Gottesman II: Schizophrenia and manicdepressive disorder: the biological roots of mental illness as revealed by the landmark study of identical twins New York, NY: Basic Books; 1994.

2. Tsuang MT, Faraone SV: The concept of target features in schizophrenia research. Acta Psychiat Scand 1999, supplement 395: 2-11.

3. Tani $P$, Lindberg $N$, Appelberg B, Nieminen-Von Wendt $T$, Von Wendt $L$, Porkka-Heiskanen T: Clinical neurological abnormalities in young adults with Asperger syndrome. Psychiatry and Clinical Neurosciences 2006 60:253-255.

4. Hollander E, Kaplan A, Schmeidler J, Yang H, Li D, Koran LM, Barbato LM: Neurological soft signs as predictors of treatment response to selective serotonin reuptake inhibitors in Obsessive-Compulsive Disorder. $J$ Neuropsychiatry Clin Neurosci 2005, 17:472-477.

5. Kodama T, Nakagawa M, Arimura K, Koriyama C, Akiba S, Osame M: Crosssectional analysis of neurological findings among healthy elderly: study in a remote island in Kagoshima, Japan. Neuroepidemiology 2002, 21:36-43.

6. Chan RCK, Chen EYH: Neurological abnormalities in Chinese schizophrenic patients. Behavioural Neurology 2007, 18:171-181.

7. Chan RCK, McAlonan GM, Yang B, Lin L, Shum D, Manschreck TC: Prevalence of neurological soft signs and their neuropsychological 
correlates in typically developing Chinese children and Chinese children with ADHD. Developmental Neuropsychology 2010, 35:698-711.

8. Jenkyn LR, Reeves AG: Neurolgic signs in uncomplicated aging (senescence). Seminars in Neurology 1981, 1:21-30.

9. Bennett DA, Beckett LA, Murray AM, Shannon KM, Goetz CG, Pilgrim DM, Evans DA: Prevalence of Parkinsonian signs and associated mortality in a community population of older people. New Engl J Med 1996, 334:71-76.

10. Jenkyn LR, Reeves AG, Warren T, Whiting RK, Clayton RJ, Moore WW, Rizzo A, Tuzun IM, Bonnett JC, Culpepper BW: Neurologic signs in senescence. Arch Neurol-Chicago 1985, 42:1154-1157.

11. Kaye JA, Oken BS, Howieson DB, Howieson J, Holm LA, Dennison K: Neurologic evaluation of the optimally healthy oldest old. Arch NeurolChicago 1994, 51:1205-1211.

12. Prakash C, Stern G: Neurological signs in the elderly. Age Ageing 1973, 2:24-28.

13. Prettyman R: Extrapyramidal signs in cognitively intact elderly people. Age Ageing 1998, 27:557-560.

14. Simpson GM, Angus JWS: Drug induced extrapyramidal disorders. Acta Psychiat Scand 1970, , supplement 212: 1-58.

15. Dazzan $P$, Morgan KD, Orr KG, Hutchinson $G$, Chitnis $X$, Suckling J, Fearon $P$, Salvo J, McGuire PK, Mallett RM, et al: The structural brain correlates of neurological soft signs in AE SOP first-episode psychoses study. Brain 2004, 127:143-153

16. Dazzan P, Morgan KD, Chitnis X, Suckling J, Morgan C, Fearon P, McGuire PK, Jones PB, Leff J, Murray RM: The structural brain correlates of neurological soft signs in healthy individuals. Cereb Cortex 2006, 16:1225-1231.

17. Chan RCK, Rao H, Chen EEH, Ye B, Zhang C: The neural basis of motor sequencing: an fMRI study of healthy subjects. Neuroscience Letters 2006 398:189-194

18. Rao H, Di X, Chan RCK, Ding Y, Ye B, Gao D: A regulation role of the prefrontal cortex in the Fist-Edge-Palm task: evidence from functional connectivity analysis. Neuroimage 2008, 41:1345-1351.

19. West RL: An application of prefrontal cortex function theory to cognitive aging. Psychological Bulletin 1996, 120:272-292.

20. Hedden T, Gabrieli JDE: Insights into the ageing mind: A view from cognitive neuroscience. Nature Reviews Neuroscience 2004, 5:87-U12.

21. Crawford JR, Bryan J, Luszcz MA, Obonsawin MC, Stewart L: The executive decline hypothesis of cognitive aging: do executive deficits qualify as differential deficits and do they mediate age-related memory decline? Aging Neuropsychol C 2000, 7:9-31.

22. Singer $T$, Verhaeghen $P$, Ghisletta $P$, Lindenberger $U$, Baltes PB: The fate of cognition in very old age: Six-year longitudinal findings in the Berlin Aging Study (BASE). Psychology and Aging 2003, 18:318-331.

23. Lin $H$, Chan RCK, Zheng LN, Yang TX, Wang Y: Executive functioning in healthy elderly Chinese people. Arch Clin Neuropsych 2007, 22:501-511.

24. Chan RCK, Wang Y, Wang L, Chen EYH, Manschreck TC, Li ZJ, Yu X, Gong QY: Neurological soft signs and their relationships to neurocognitive functions: a re-visit with the structural equation modeling design. Plos One 2009, 4:e8469.

25. Wang ZY, Zhang MY, Qu GY, Chen JX, Zhao J: The application of the Chinese version of Mini Mental State Examination. Shanghai Psychiatry Medicine 1989, 7:108-111

26. Zhang MY, Qu GY, Jin H, Cai GJ, Wang ZY: Commparison of measures for dementia. Chinese Journal of Psychiatry 1991, 24:194-196 (in Chinese).

27. Chen EYH, Shapleske J, Luque R, Mckenna PJ, Hodges JR, Calloway SP, Hymas NFS, Dening TR, Berrios GE: The Cambridge Neurological Inventory: a clinical instrument for assessment of soft neurological signs in psychiatric patients. Psychiat Res 1995, 56:183-204.

28. Chen EYH, Chan RCK: The Cambridge Neurological Inventory: clinical, demographic, and ethnic correlates. Psychiat Ann 2003, 33:202-210.

29. Lam LCW, Lui WWC, Chiu HFK: Association beween soft neurological signs and clinical progression Alzheimer's disease. Hong Kong Journal of Psychiatry 2005, 15:43-49.

30. Gong YX, Jiang DW, Deng JL, Dai ZS, Zhou QZ, Xie GY, Li Y, Hua XX: Manual of Wechsler Memory Scale: Chinese version Changsha: Hunan Medical College; 1989.

31. Chan RCK, Wang Y, Deng YY, Zhang YN, Yiao XL, Zhang C: The development of a Chinese equivalence version of Letter-Number Span Test. Clin Neuropsychol 2008, 22:112-121.
32. Hu L-t, Bentler PM: Cutoff criteria for fit Indexes in covariance structure analysis: conventional criteria versus new alternatives. Structural Equation Modeling 1999, 6:1-55.

33. Martins I, Lauterbach M, Slade P, Luis H, DeRouen T, Martin M, Caldas A, Leitao J, Rosenbaum G, Townes B: A longitudinal study of neurological soft signs from late childhood into early adulthood. Dev Med Child Neurol 2008, 50:602-607.

34. Arango C, Bartko JJ, Gold JM, Buchanan RW: Prediction of neuropsychological performance by neurological signs in schizophrenia. Am J Psychiat 1999, 156:1349-1357.

35. Chan RCK, Chen EYH: Blink rate does matter: a study of blink rate, sustained attention, and neurological signs in schizophrenia. J Nerv Ment Dis 2004, 192:781-783.

36. Flashman LA, Flaum M, Gupta S, Andreasen NC: Soft signs and neuropsychological performance in schizophrenia. Am J Psychiat 1996, 153:526-532.

37. Freedman R, Coon H, Myles-Worsley M, Orr-Urtreger A, Olincy A, Davis A, Polymeropoulos M, Holik J, Hopkins J, Hoff M, et al: Linkage of a neurophysiological deficit in schizophrenia to a chromosome 15 locus. $P$ Natl Acad Sci USA 1997, 94:587-592.

38. Egan MF, Straub RE, Goldberg TE, Yakub I, Callicott JH, Hariri AR, Mattay VS, Bertolino A, Hyde TM, Shannon-Weickert C, et al: Variation in GRM3 affects cognition, prefrontal glutamate, and risk for schizophrenia. P Natl Acad Sci USA 2004, 101:12604-12609.

39. Communiqué on major data of $1 \%$ National Population Sample Survey in 2005. 2010 [http://www.stats.gov.cn/was40/gjtij_en_detail.jsp? searchword $=2005 \&$ channelid $=1175 \&$ record $=23$.

40. Evans DA, Funkenstein HH, Albert MS, Scherr PA, Cook NR, Chown MJ, Hebert LE, Hennekens CH, Taylor JO: Prevalence of Alzheimer's disease in a community population of older persons: higher than previously reported. JAMA 1989, 262:2551-2556.

41. Sanders RD, Joo YH, Almasy L, Wood J, Keshavan MS, Pogue-Geile MF, Gur RC, Gur RE, Nimgaonkar VL: Are neurologic examination abnormalities heritable? A preliminary study. Schizophrenia Research 2006, 86:172-180.

doi:10.1186/1744-9081-7-32

Cite this article as: Chan et al:: Neurological abnormalities and neurocognitive functions in healthy elder people: $A$ structural equation modeling analysis. Behavioral and Brain Functions 2011 7:32.

\section{Submit your next manuscript to BioMed Central and take full advantage of:}

- Convenient online submission

- Thorough peer review

- No space constraints or color figure charges

- Immediate publication on acceptance

- Inclusion in PubMed, CAS, Scopus and Google Scholar

- Research which is freely available for redistribution

Submit your manuscript at www.biomedcentral.com/submit
Ciomed Central 